\title{
Coronavirus: a catalyst for change and innovation
}

\author{
Anne-Laure Mention \\ anne-laure.mention@rmit.edu.au | RMIT University, Australia \\ João José Pinto Ferreira \\ jjpf@fe.up.pt | INESC Technology and Science, Faculty of Engineering, University of Porto, Portugal \\ Marko Torkkeli \\ marko.torkkeli@lut.fi | Lappeenranta University of Technology, Finland
}

Man's existence lies in his integrity. A man without integrity can exist merely through his luck.

- Analects of Confucius, VI: 19

As we write this editorial, people around the world are apprehensive about their future; some are at home; some are thinking about the loved ones they cannot visit; some, unfortunately, are dying. We watch the graphs and listen to the daily news of new coronavirus cases, but be it just one or one thousand, for the those close of the ones affected, the impact is catastrophic.

The impact of coronavirus, named COVID-19, was rapid in most industries, affecting both supply and demand. Airport Council International (ACI) reported that global air traffic declined at the rate of $2 \%-5 \%$ in January 2020 compared to previous month. Significantly larger drops are to follow as airlines ground nearly $75 \%$ of their fleet due to domestic and international travel restrictions as governments try to contain the spread of coronavirus (Kotoky, Stringer and Saxena, 2020). Similar stories are reported on ground with TomTom live traffic index suggesting that road mobility is down by $75 \%$ in some of the world's busiest cities like Milan, Paris, Manchester and Boston (Marchant, 2020).

The world is a different place. Recent studies in psychology post COVID-19 found that people are experiencing higher levels of anxiety, depression and indignation compared to period before the pandemic (Li et al., 2020). What we have come to believe through our previous experiences is being challenged. Dissonance as we struggle to maintain cognitive consistency between what we believe out to be and what the situation demands of our actions (Festinger, 1957). World leaders are facing difficult decisions, trying to reduce cognitive inconsistencies between actions required in their role as heads of state and their own beliefs on the value of human life. Some have argued 
that this is no simple economic trade-off (Cohen, 2020; Mahoney, 2020), and that controlling coronavirus and maintaining economic prosperity are indeed intertwined. Mahoney (2020) goes on to claim that the mere debate of trade-offs in the coronavirus situation is disingenuous. Every event creates new opportunities, besides the challenges. Coronavirus has created unprecedented demand for several products and services from face masks, to ventilators to online and homedelivery. When efforts are put towards these new demands, it not only helps to cope with the health catastrophe but also helps the economy but redirect flow of funds, creating new markets and new job opportunities. Even the government relief incentives to boost economies and support now jobless employees are not a trade-off against productivity. The difference in this situation as compared to other economic events (e.g. the Global Financial Crisis) is that right now we do want people to stay home, which diminishes the value of argument that providing job seeker payments to individuals will affect future productivity. Indeed, our assumption is that a lesson from current coronavirus situations would be that people will become more vigilant of their finances and more appreciative of opportunities that come their way. Perhaps this is just our optimism in an effort to stay positive or perhaps it is a way we are reducing dissonance, MK Gandhi's quote: "It is health that is real wealth and not pieces of gold and silver".

No matter what the personal situation, as a witness of these overwhelming events, one cannot ignore the importance of 'being human'- a notion that involves purposeful actions that conform to the principles of fairness, wellness and integrity. While fairness (being impartial or nondiscriminatory) is relative and guided by societal values (Franke, Keinz and Klausberger, 2013), wellness (state of being in good health) and integrity (quality of being honest) are rooted in the inside-out or intrinsic intention-behaviour (Rutter \& Quine, 2002).

Our readers who familiarise with Fédération Internationale de Football Association's (n.d.) version of fairness, would know that Winning is not fun if achieved unfairly". This notion of fairness is relatively simple to understand - it is about idea of being true to oneself in this world. The fairness value concept is ingrained in our societies, the feeling of unfairness is something we feel from a very young age. Just think of a case when a kid gets one candy and the other gets two. The one who did not receive two candies may feel it to be unfair in normal circumstances. But what if you told them that the kid who got two candies is sick. Would the kid who felt unfair initially suddenly feel that their dissonance is reduced? Perhaps, since now they have additional information which helps them to reframe the action (Festinger, 1957). The belief of what action is fair gets reframed when survival is at stake, such as in the current world-wide pandemic. Greed emerges as fears of some are recognised as opportunities by others.

The hierarchy of needs proposed by Abraham Maslow and discussed in a Letter from Academia published in the Journal of Innovation Management (Venter, 2016) explains how individuals and even societies can close as greed and self-preservation takes over considerations of fairness. We have recently been witnessing richer bidders getting key medical materials, which were already bought and promised, diverted to higher bidders. However, there is still hope in humanity as examples of innovations that embrace the principles of being human continue to rise. It is clearly a wake-up call for individuals and nations alike. The innovation climate which has been unbalanced before coronavirus with short-sighted willingness to pursue profits against long-term humanistic approach to sustainability is being reshaped. Bureaucracy and closed mindset are being challenged. Open innovation is being promoted to embed trust amongst wide and varied 
stakeholders, under the premise that 'trust is the conditio sine qua non of any kind of social, business-oriented interaction and cooperation (Salampasis, Mention and Torkkeli, 2015, p. 52). Trust in others being fair drives willingness to contribute by encouraging learning, experimentation and investment in long-term value creation efforts (Dahlander and Gann, 2010). An example of this is the exchange of information and anti-malaria drugs between Indian and US governments in a combined effort to combat COVID-19 pandemic. Open government communities have also been looking at ways to apply principles of transparency, accountability and participation to build trust and promote fairness innovation efforts. Several countries have initiated open platforms to engage world audience through hackathons, whatsapp groups, social media campaigns, social contact tracing technologies and online education, amongst others (see full list by country at: https: //www.opengovpartnership.org/collecting-open-government-approaches-to-covid-19/)

Innovation in the COVID-19 times is happening at a rapid pace and in the most inspiring ways. Universities, industry and governments are working together in rapid testing and rollout of innovations, with best available evidence translated into practice within days or even hours. Digitaldiagnosing is becoming a routine as medical associations relax the status quo and provide guidance to practitioners on use of online diagnostic technologies (Downey, 2020). The academic community has also been quick to chip in by turning around collaborative initiatives, experiments with emerging technologies and publishing studies at a rapid pace. For example, Australian RMIT University's Health Transformation Lab has partnered with social enterprise MediStays to launch path-breaking accommodation service, connecting patients, families and health workers in times of social isolation. The same university has also begun trials of new type of face mask that can be worn for longer durations by health workers. Likewise, Oxford University's Centre for Evidence-based Medicine has established a COVID-19 evidence service to provide rapid response to primary care questions (see https://www.cebm.net/oxford-covid-19-evidence-service/). European Pharmaceutical industry has banded together as part of the Innovative Medicines Initiative (an EU-wide H2020 Research and Innovation Action, Call 21) to search for vaccines, supply medicines to patients and support government and health systems on the ground. GM, Ford, and Tesla have joint forces and transformed some of their manufacturing capacity to assemble much needed ventilators. Likewise, British Formula 1 team and Dyson are collaborating to redesign the ventilator by reframing the design challenge as one that captures need and speed. Besides these, every day now there are numerous stories of entrepreneurial efforts and innovations emerging, from virtual stylists, apps to encourage good neighbours, to hilarious was of raising money for COVID-19 relief efforts (see full list by industry sector at: https://www.covidinnovations.com/).

Coronavirus COVID-19 is clearly a catalyst of change. But, amidst such rapid change, there lies risks and lessons for future. Foremost risk is that while for most young people engaging online may not be unusual, it perpetuates inequalities in absence of choice for our most vulnerable population - the elderly, disabled and those experiencing poverty or social exclusion. The lesson for innovating firms is that no matter where it is in the digital maturity spectrum, the focus now needs to be on finding new ways to embrace affordance-effectivity fit and creating new products and services by reframing the innovation challenge. Our central message for the innovation community is that traditional ways of framing an innovation problem based on business benefits 
are no longer sufficient and a humanistic approach is needed. Such an approach has the user at its kernel and is based on the principles of fairness and wellness.

Finally, it seems clear that, for the benefit of all, the pandemic is no excuse to relax core principles of integrity \& fair play, for that reason, and in the context of this Journal, we would like to ask our readers and authors of papers under review to give us and reviewers' time. At this point in time, we are not putting pressure on the reviewers, it is likely that many are working from home, with kids around and loaded not only with the usual work, but also having to cope with the home chores. Integrity \& fair Play are deeply entwined in JIM's DNA.

Wish you all well. Thank you for your trust and commitment to JIM.

Innovatively yours,

Anne-Laure Mention, João José Pinto Ferreira, Marko Torkkeli

Founding Editors

\section{References}

Cohen, J., 2020. 'There's no trade-off between targeting coronavirus and restarting the economy - they're intertwined', Forbes, 26 March, viewed 20 April 2020, https://www.forbes.com/sites/ joshuacohen $/ 2020 / 03 / 26 /$ tradeoff-between-public-health-measures-targeting-covid-19-and-the-economy-is-a-fa \#3f4ec01260d2

Downey, A., 2020. 'GPs urged to go digital to prevent spread of coronavirus', Digital Health, 10 March, viewed 20 April 2020,

https://www.digitalhealth.net/2020/03/gps-urged-to-go-digital-to-prevent-spread-of-coronavirus/

Dahlander, L. and Gann, D.M., 2010. How open is innovation? Research policy, 39(6), pp.699709.

Fédération Internationale de Football Association's (n.d.). Fair Play. FIFA, viewed 20 April 2020, https://grassroots.fifa.com/en/for-kids/11-for-health/fifa-fair-play.html

Festinger, 1957. A theory of cognitive dissonance. Stanford, CA: Stanford University Press.

Franke, N., Keinz, P. and Klausberger, K., 2013. "Does this sound like a fair deal?": Antecedents and consequences of fairness expectations in the individual's decision to participate in firm innovation. Organization science, 24(5), pp.1495-1516.

Kotoky,A., Stringer D., and Saxena, R., 2020. 'Two-thirds of the world's passenger jets are grounded amid COVID-19 pandemic: here's what that means', Time, 9 April, viewed 20 April 2020, https://time.com/5823395/grounded-planes-coronavirus-storage/

Li, S., Wang, Y., Xue, J., Zhao, N. and Zhu, T., 2020. The impact of COVID-19 epidemic declaration on psychological consequences: a study on active Weibo users. International journal of environmental research and public health, 17(6), p.2032.

Mahoney, N., 2020. 'Don't fall for the false trade-offs of COVID-19 policy', Chicago Booth Re- 
view, 26 March, viewed 20 April 2020, https://review.chicagobooth.edu/economics/2020/article/ don-t-fall-false-trade-offs-covid-19-policy

Marchant, A., 2020. 'What can traffic data tell us about the impact of coronavirus?', TomTom, 17 April, viewed 20 April 2020, https://www.tomtom.com/blog/moving-world/covid-19-traffic/

Rutter, D., \& Quine, L. (2002). Social cognition models and changing health behaviours. In D. Rutter \& L. Quine (Eds.), Changing health behaviour: Intervention and research with social cognition models (p. 1-27). Open University Press.

Salampasis, D.G., Mention, A.L. and Torkkeli, M., 2015. Trust embeddedness within an open innovation mindset. International Journal of Business and Globalisation, 14(1), pp.32-57.

Venter, H.J., 2016. Self-transcendence: Maslow's answer to cultural closeness. Journal of Innovation Management, 4(4), pp.3-7.

FIFA: https://grassroots.fifa.com/en/for-kids/11-for-health/fifa-fair-play.html. 